\title{
HYDROSTATIC SYSTEMS FOR ENERGY RECUPERATION IN EARTHMOVING MACHINES
}

\author{
UDC (621.879.31:620.9)
}

\section{Vesna Jovanović, Dragoslav Janošević, Ivan Ćirić, Jovan Pavlović}

University of Niš, Faculty of Mechanical Engineering, Republic of Serbia

\begin{abstract}
The first part of the paper contains the results of a study into the change in the energy parameters of earthmoving machines during manipulation tasks. The results of the research show that during certain operations of manipulation tasks, in the stop phase, the required energy of the machines has negative values. Modern earthmoving machines have hydrostatic drive systems that accumulate potential negative energy by recuperation and, if necessary, return it to the drive system of the machine for use in other operations of a manipulation task. In the second part of the paper, the analysis of the concepts of hydrostatic drive systems of earthmoving machines that enable energy recuperation is performed in detail.
\end{abstract}

Key words: earthmoving machines, energy recuperation

\section{INTRODUCTION}

Modern technical systems are developed according to the criteria of sustainable development, which, among others, also includes the criterion of energy efficiency of a system. The last two decades have witnessed intensified research related to the development of energy efficiency of drive systems of mobile (construction, transport, mining, agricultural and communal) machines [1-5]. The obtained research results have already been applied to new models of earthmoving machines with hybrid drive systems and energy recuperation systems that reduce fuel consumption and environmental pollution [6]. It is characteristic for earthmoving machines that, when performing primary functions of intermittent transportation of different materials and objects, energy efficiency is very variable. The reason for the variable energy efficiency of earthmoving machines is a cyclic mode of operation in very different operating conditions with operations of a manipulation task in which the accelerating and decelerating (stopping) phases of the movement of members of the kinematic chain of machines occur. Under such conditions and the mode of operation of

Received October 12, 2019

Corresponding author: Vesna D. Jovanović

Faculty of Mechanical Engineering, Aleksandra Medvedeva 14, 18000 Niš, Republic of Serbia

E-mail: vesna.jovanovic@masfak.ni.ac.rs 
earthmoving machines, there is an operation in which the maximum or partial power of the drive system is used, but there is also a phase of individual operations when the power of the drive system is not required, yet there is a need to stop the inertial movement of members of the kinematic chain of the machine. A typical example is the change in the power drive system of a hydraulic excavator while performing manipulation tasks. The diagram in Fig. 1a shows the change in the required power of the drive mechanisms: the slewing platform $N_{2}$, boom $N_{3}$, stick $N_{4}$, and bucket $N_{5}$ of a hydraulic crawler excavator weighs $16000 \mathrm{~kg}$ with a $0.6 \mathrm{~m}^{3}$ bucket volume during a manipulation task with the following operations: digging, transporting material from the digging level to the level of unloading, unloading and returning to the new digging level [7]. The diagram shows that in all drive mechanisms of the excavator there are also negative power values that result from the inertial movement of the members of the kinematic chain of the excavator at the stop phases in all operations of the excavator manipulation task. The higher values of the inertial and potential energy at the stop phases of the operation of the manipulation task have the members of the kinematic chain with a higher mass (slewing platform and boom). Even for loaders, energy efficiency varies significantly when performing the primary function of excavating, transporting and unloading materials [8]. The diagram in Fig.1b shows the change in the required power of the drive mechanisms: the $N_{1}$ motion control system of the support and movement mechanism, boom $N_{3}$ and bucket $N_{4}$ of the loader manipulator for the duration of the manipulation task with operations of digging, lifting, emptying the bucket and returning to a new position.
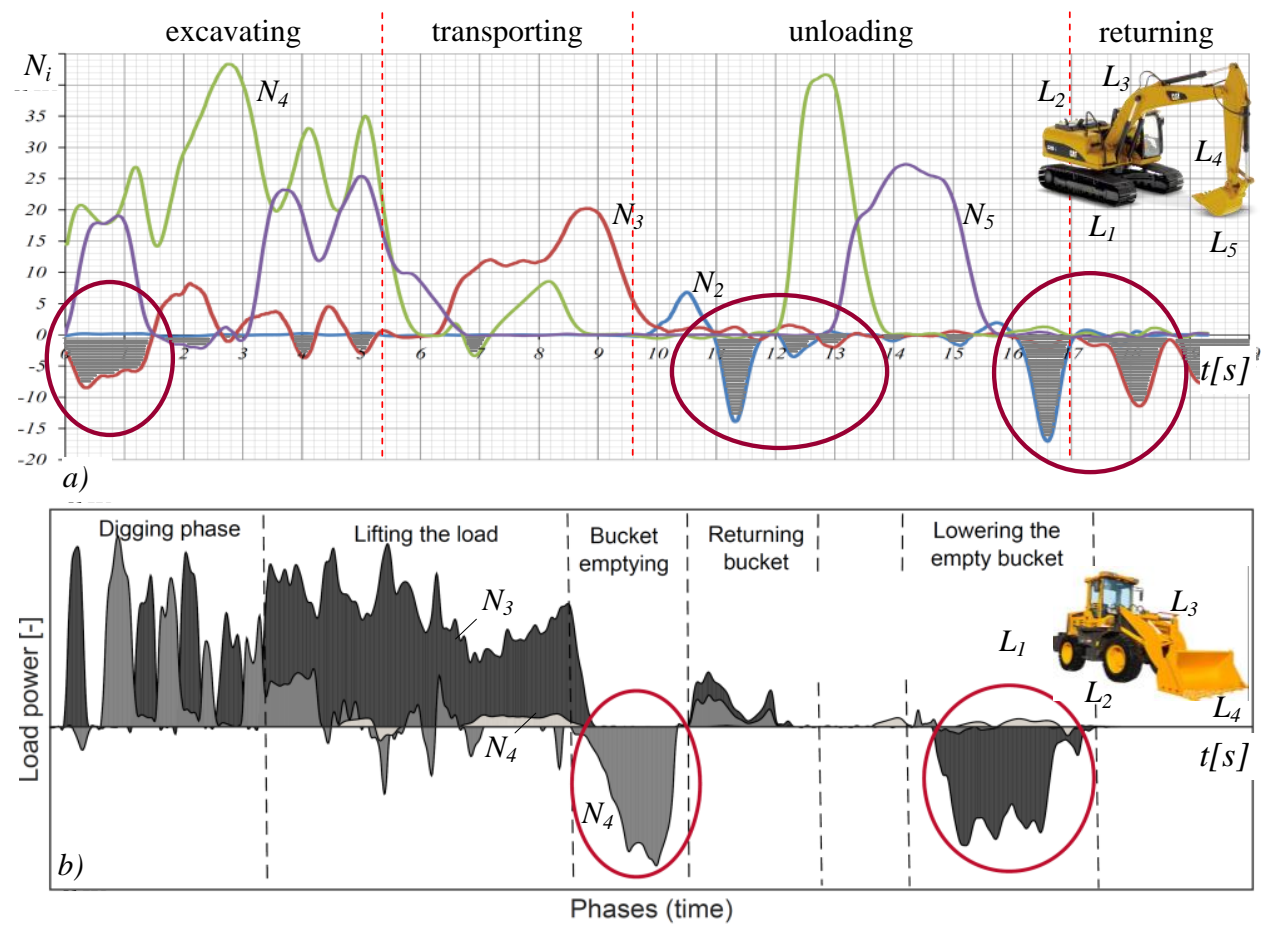

Fig. 1 Power of the drive mechanisms: a) hydraulic excavator [7], b) wheel loader [8] 
The diagram shows the negative values of power in the individual stop phases of all operations of the manipulation task, which have the highest values at the stages of emptying the bucket and returning the manipulator to a new position plane.

With older excavator and loader drive systems, as well as other earthmoving machines, inertial and potential energies in the stop phases of operations are converted by braking systems into heat and irretrievable loss, thus reducing the energy efficiency of the machines.

In the following sections, hybrid drive systems, which, through energy recuperation, achieve higher energy efficiency of hydraulic excavators, will be analyzed.

\section{ENERGY RECUPERATION OF EXCAVATOR}

The pursuit of research to date regarding the energy efficiency of hydraulic excavators and other earthmoving machines has been directed toward the following objectives:

- reduction of system component losses (diesel engines, hydraulic pumps, hydraulic motors, hydraulic cylinders and distribution valves),

- energy recuperation of the system,

- managing the parameters of the drive system so that they are adapted to the operating conditions of the machines.

According to the set goals, various hybrid drive systems and control systems for hydraulic excavators have been developed, the concepts of which are based on: a) hydraulic transformers and b) distribution valves.

\subsection{Hybrid drive systems with hydraulic transformers}

Hybrid drive systems for energy recuperation with hydraulic transformers have been developed intensively in recent years and are in the phase of experimental testing on small hydraulic excavators of mass up to $5000 \mathrm{~kg}$ (Fig.2a) [9][10]. In principle, a general model of a hybrid drive system with transformers of a hydraulic crawler excavator (Fig. 2) with a slewing platform and load manipulator with a boom, stick and bucket contains: a drive diesel engine 1 which drives the main hydraulic pump 3.1 and the auxiliary 3.2 hydraulic pump. By its pressure line the main hydraulic pump feeds the following actuators: hydraulic motors for driving continuous tracks $C_{1}$, hydraulic transformers $C_{2}$ for drive platform rotation and hydraulic cylinders of boom $C_{3}$, stick $C_{4}$, and bucket $C_{5}$. An accumulator 3.2 is connected to the pressure line of the hydraulic pump.

The hydraulic transformers 4 , type PM-1, are connected by their lines $A$ and $B$ to the working lines of the actuators $C_{1}-C_{5}$ of the drive mechanism of the excavator, and to the line $\mathrm{T}$ to the return line of the hydraulic pump or reservoir of the system. Due to the very rare overlap of the functions of the mechanism of the stick and the bucket with the movement function of the excavator, there is a common transformer for the hydraulic cylinder of the stick and the hydraulic motor of one track, i.e. for the hydraulic cylinder of the bucket and the hydraulic motor of the other track. The activation priority of these transformers is determined by the set of distribution valves 6 . 


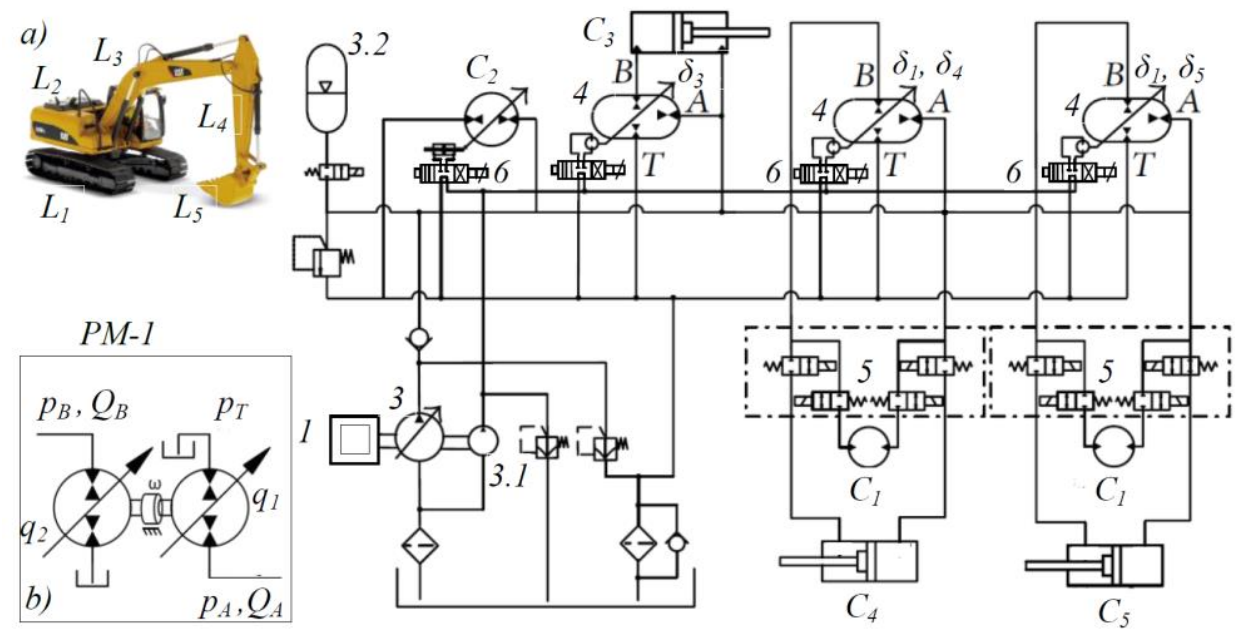

Fig. 2 Hybrid drive systems of a hydraulic excavator with transformers a) kinematic chain of excavator [10] b) type PM-1 transformer [9]

The transformers used in the excavator drive system consist of a variable-flow hydraulic pump and a hydraulic motor $q_{1}$ and $q_{2}$ (Fig. 2b). For type PM-1 transformers, the suction line of the hydraulic pump and the return line of the hydraulic motor are connected to the reservoir of the system and the pressure line of the hydraulic pump to the pressure line of the main hydraulic pump or the accumulator while the pressure line of the hydraulic motor is connected to the working line of the actuator, i.e. the hydraulic cylinder. The transfer functions of type PN-1 transformers are determined by the equations:

$$
\begin{gathered}
J \dot{\omega}=\left(p_{A}-p_{T}\right) \frac{q_{1}}{2 \pi} u_{1}+\left(p_{T}-p_{B}\right) \frac{q_{2}}{2 \pi} u_{2}-b_{t} \omega-M_{t}, \\
Q_{A}=\omega \frac{q_{1}}{2 \pi} u_{1}-Q_{g}, \\
Q_{B}=-\omega \frac{q_{2}}{2 \pi} u_{2}-Q_{g},
\end{gathered}
$$

where: $q_{1}, q_{2}$ - the maximal values of the specific flow of the hydraulic pump and the hydraulic motor, $p_{A}, p_{B}$ - the pressures in the transformer lines, $u_{1}, u_{2}$ - the ratio of the current and the maximum specific flow of the hydraulic pump and the hydraulic motor, $b_{t}$ - the damping coefficient, $M_{t}$ - the transformer friction torque, $\omega, \dot{\omega}$ - the angular velocity and the angular acceleration of the common shaft of the hydraulic pump and the hydraulic motor, $J$ - the moment of inertia of the transformer, $Q_{A}, Q_{B}$ - the flows in the transformer lines, $Q_{g}$ - the loss of flow. Hybrid drive systems with transformers can optimize system parameters depending on the operating conditions of the excavator by monitoring the parameters of the size of the operating condition of the excavator and changing the control sizes. 
Variable excavator operating parameters refer to the change in the diesel engine parameters and the actuator parameters of the excavator drive mechanisms covered by the set of sizes (Table 1) [10]:

$$
P=\left\{n_{e n}, n_{2}, p_{31}, p_{41}, p_{51}, p_{h}, v_{3}, v_{4}, v_{5}\right\},
$$

Table 1 Excavator operating state sizes

\begin{tabular}{lcc}
\hline System Name & Mark & Unit \\
\hline Diesel engine rpm & $n_{e}$ & $\mathrm{~min}^{-1}$ \\
Platform rpm & $n_{2}$ & $\mathrm{~min}^{-1}$ \\
Pressure of the boom cylinder on the piston side & $p_{31}$ & $\mathrm{~Pa}$ \\
Pressure of the stick cylinder on the piston side & $p_{41}$ & $\mathrm{~Pa}$ \\
Pressure of the bucket cylinder on the piston side & $p_{51}$ & $\mathrm{~Pa}$ \\
Pressure in the pressure line of the hydrostatic system & $p_{h}$ & $\mathrm{~Pa}$ \\
Boom cylinder speed & $v_{3}$ & $\mathrm{~m} / \mathrm{s}$ \\
Stick cylinder speed & $v_{4}$ & $\mathrm{~m} / \mathrm{s}$ \\
Bucket cylinder speed & $v_{5}$ & $\mathrm{~m} / \mathrm{s}$ \\
\hline
\end{tabular}

The control quantities of a hybrid drive system are determined by the set:

$$
c=\left\{\beta_{e}, \beta_{p}, \beta_{1}, \beta_{2}, \delta_{3}, \delta_{4}, \delta_{5}\right\},
$$

which regulates the parameters of: diesel engines $(\beta e)$, hydraulic pump $(\beta p)$, slewing platform drive $(\beta 2)$, boom drive mechanisms $(\delta 3)$, drive mechanisms of one stick and one track $(\delta 4)$, and drive mechanism of the bucket and the other track $(\delta 5)$.

The change of control sizes is achieved by electro-hydraulic distributor valves 6 (Fig. 2), powered by the auxiliary hydraulic pump 3.1 and activated by a microcontroller programmed with an optimization dynamic algorithm. Changing the size of the hybrid drive system control depends on the excavator operating state and transformer parameters.

For example, the size of the platform's slew control is determined by the equation:

$$
\beta_{2}=\frac{2 \pi}{p_{h} \cdot q_{2}}\left(M_{2}+\operatorname{sign}\left(n_{2}\right) \cdot\left|M_{t}\right|\right),
$$

where are: $M_{2}$ - the load moment of the slewing platform mechanism, $M_{t}$ - the friction moment in the slewing platform mechanism, $p_{h}$ - the pressure of the main hydropump, i.e. the battery, $q_{2}$ - the hydromotor specific flow of the slewing platform mechanism.

\subsection{Recuperation systems with distribution valves}

In the first variant, the diesel engine 1 (Fig. 3) drives a hydraulic pump $3 L$, which via the distributor 4.L2-4.2L5 drives the following actuators: hydromotor $C_{2}$ of the slewing platform drive $L_{2}$ and hydraulic cylinders $C_{3}-C_{5}$ of the drive mechanism of the boom $L_{3}$, stick $L_{4}$ and bucket $L_{5}$. In the stopping phases of the operation of the excavator manipulation task, the inertial and potential energy of the members of the kinematic chain of the excavator is, via the actuators (hydraulic cylinders and hydraulic motors), transformed into hydrostatic energy, which is accumulated in the $3 S$ batteries via the 4.S2-4.S5 distribution valves. In the accelerated phases of the operation of the excavator 
manipulation task, the accumulated energy, via the distributor 4, drives the actuators of the slewing platform drive mechanism and the manipulator drive mechanisms, thereby engaging the smaller power of the hydraulic pump $3 L$, i.e. the diesel engine 1 , in turn achieving the energy efficiency of the excavator. Hybrid drives of modern excavators have energy recuperation systems for drive mechanisms with an actuator in the form of a hydraulic cylinder (Fig.4a) and a hydraulic motor (Fig.4b).

In the case of an energy recuperation system with a hydraulic cylinder $C_{i}$ (Fig.4a) as an actuator of the drive mechanism at the stopping phases of movement of members of the kinematic chain of the excavator to which the hydraulic cylinder is connected, inertial and potential energy occurs and is transformed into hydrostatic energy in the hydraulic cylinder. Through the distributor $4 L$ and distributor valve $4 S$, the resulting hydraulic energy is accumulated in the hydraulic accumulator $3 S$. The accumulated energy is restored to the excavator drive system by starting the hydraulic motor $3 M$, i.e. generator 2.3 where electricity is generated, which, through inverter 2.1 , recharges battery 2.2 and powers the electric motor 2 . With the energy recovered, the electric motor drives the main hydraulic pump $3 L$ to reduce the power required by the diesel engine $l$ while increasing the overall energy efficiency of the excavator.

For the energy recuperation system with hydromotor $C_{2}$ (Fig.3b) as an actuator of the driving mechanism of the excavator slewing platform, during the platform acceleration phase, the oil flow through the hydraulic motor increases, however, the hydraulic motor rarely achieves the number of rotations corresponding to the maximum flow rate of the $3 L$ hydropump because the platform rotation angle is relatively small (about $90-130^{\circ}$ ) and is reached before the hydraulic motor reaches the maximum number of rotations. When stopping rotation, the kinetic energy of the platform is converted to hydraulic energy via a hydraulic motor, which then changes its function to that of the hydraulic pump. To utilize the available energy, the hydraulic system of the slewing platform drive system is added: a battery $3 S$, two non-return valves 4.3 and 4.4 and four non-return control valves $4 S 4$. The pressure setting level of the $4 S 4$ valve is slightly lower than the battery pressure

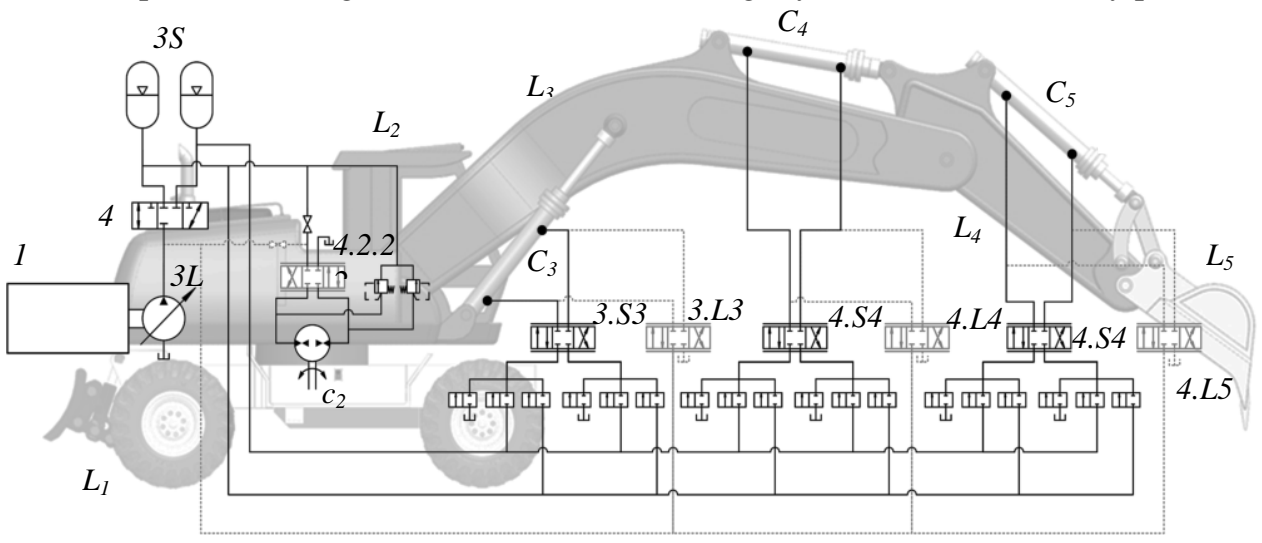

Fig. 3 Hybrid drive systems of hydraulic excavators with distribution valves [11]

after braking the hydraulic motor. When the operator starts the hydraulic motor with a joystick through the distributor $4 L$, the hydraulic pump oil flow is greater than what the hydraulic motor requires, and the excess oil is charged to the $3 S$ battery via the $4 S 2$ or 
$4 S 4$ valve (depending on the platform turning direction) instead of overflowing through the $4 S 1$ main safety valve. As the hydraulic motor accelerates, the flow rate used by the hydraulic motor increases. When the flow of the hydraulic motor equals the flow of the hydraulic pump, then the pressure in the system decreases, and at the same time the battery releases the accumulated energy to the hydraulic motor. When the maximum speed of the hydraulic motor is reached, the battery is nearly discharged and can be recharged with energy generated when the platform is stopped. When the hydraulic motor stops, the valves $4 S 2$ (depending on the platform direction of rotation) are closed. As the platform still rotates, its torque due to inertia turns the motor. The hydraulic motor then operates as a hydraulic pump, discharges the battery, and the oil is forced to go over the safety valve $4 S 6$. As the battery is charged with oil, the pressure in the accumulator rises, the brake torque of the platform is formed, and at the same time the energy generated by the braking is accumulated in the accumulator. As soon as the platform has passed the stopping phase, the battery is charged with the platform's stopping energy.

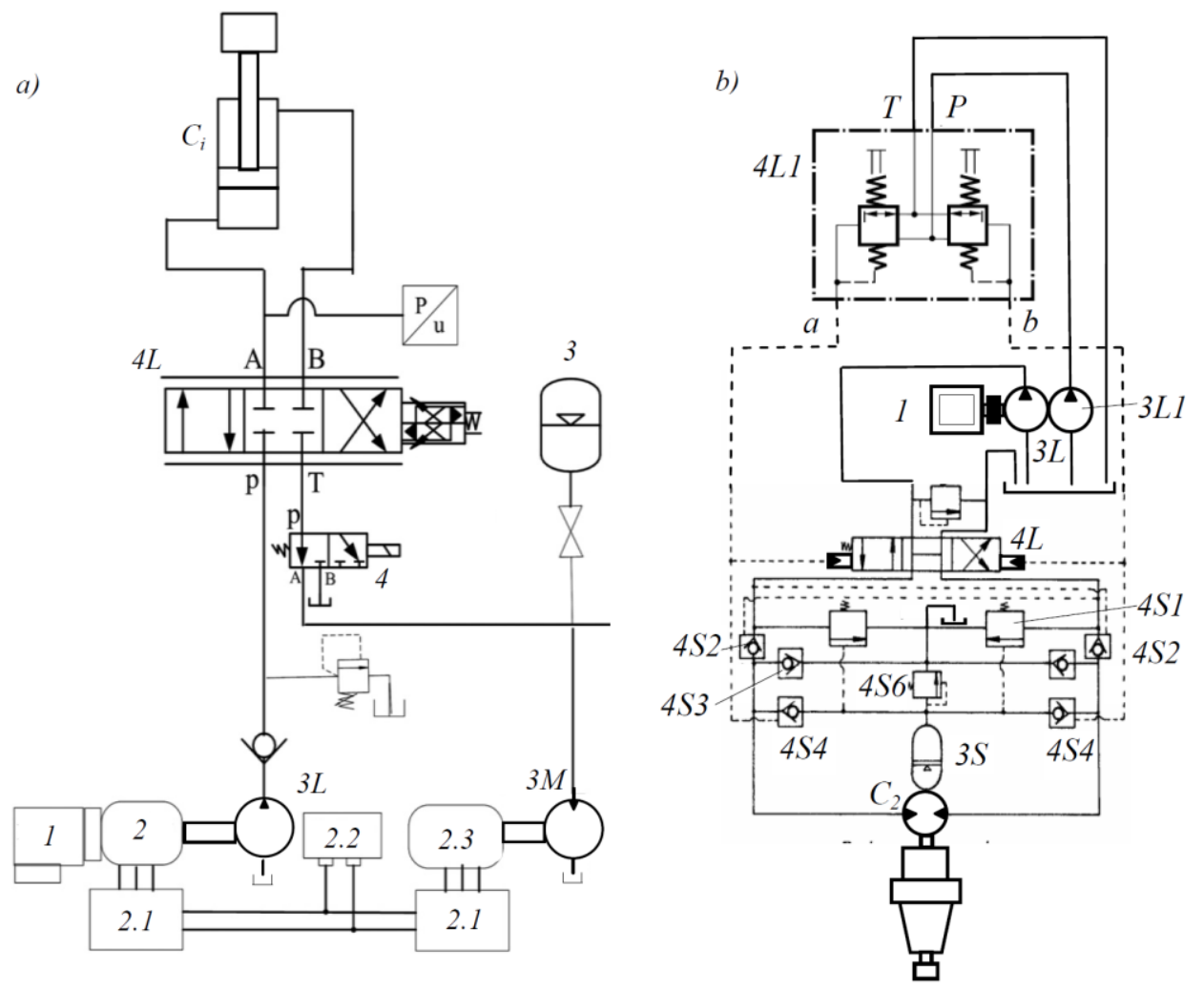

Fig. 4 Systems for power recuperation of drive mechanisms with actuators in the form of: a) hydraulic cylinder [12], b) hydraulic motor [13] 


\section{CHARACTERISTICS OF THE SYSTEM FOR ENERGY RECUPERATION}

Research has been carried out to assess the importance of energy recuperation [7], energy efficiency of a hydraulic excavator, weighing $16000 \mathrm{~kg}$, with a load manipulator and a hybrid drive system when operating with and without a system for energy recuperation.

Some of the results of the research carried out are presented in the diagram (fig. 5), which shows the change of torque and specific fuel consumption of the diesel engine of the excavator drive system depending on the change in the speed of the diesel engine during the operation of the excavator with and without the energy recuperation system. The diagram shows that, when the drive system of the excavator operates without the energy recuperation system, the diesel engine operates in the maximum power area with increased speed, higher fuel consumption and greater torque change.

In case the excavator's drive system works with the energy recuperation system, the diesel engine works in the maximum torque zone with reduced power at lower speed, less fuel consumption and with less torque change. As far as the energy efficiency of the excavator is concerned, under the same working conditions and similar manipulation tasks, the research has shown that the diesel engine of a hybrid drive with an energy recuperation system consumed about $27 \%$ less fuel than the same excavator with a drive without an energy recuperation system.

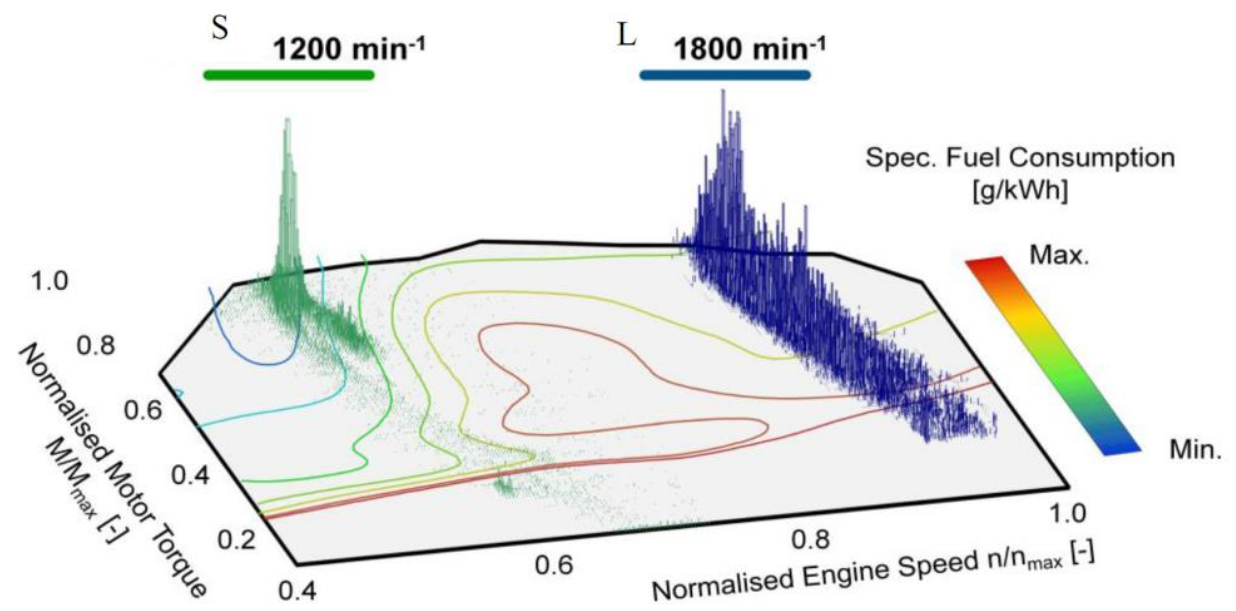

Fig. 5 Characteristics of the diesel engine of the drive system of the excavator in operation with and without the energy recuperation system [11]

\section{CONCLUSION}

The paper presents the results of the research which shows that in the stopping phases of certain operations of manipulation tasks of hydraulic excavators and loaders considerable inertial and gravitational energies occur that can be recovered and returned to the drive system of machines and increase their energy efficiency. The analysis conducted in this paper shows that, based on the researches carried out so far, different 
hybrid energy recuperation systems have been developed for mobile machines, whose concepts are based on hydrostatic transformers and valves. In hybrid drive systems, hydrostatic transformers and distribution valves are used to recuperate the energy of drive mechanisms that have hydro cylinders and hydraulic motors for actuators. Hybrid drive systems with transformers and distribution valves have the ability to optimize the parameters of the drive system of the machines by monitoring the parameters of the size of the operating state and the parameters of the state of the machine control system.

Acknowledgement: This paper presents the results of the research conducted within the project "Research and Development of New Generation Machine Systems in the Function of the Technological Development of Serbia" funded by the Faculty of Mechanical Engineering, University of Niš, Serbia.

\section{REFERENCES}

[1] P. Casoli, L. Riccò, F. Campanini, A. Bedotti, "Hydraulic Hybrid Excavator-Mathematical Model Validation and Energy Analysis", Energies, 9(12), 1002; https://doi.org/10.3390/en9121002, 2016.

[2] M. Heikkilä, Energy Efficient Boom Actuation Using a Digital Hydraulic Power Management System,Tampereen teknillinen yliopisto - Tampere University of Technology, Tampere 2016.

[3] K. Heybroek, J. Larsson, J. Palmberg, The potential of energy recuperation in valve controlled mobile hydraulic systems, The 11th Scandinavian International Conference on Fluid Power, SICFP'09, June 2-4, Linköping, Sweden, 2009.

[4] J. Nokka, "Energy efficiency analyses of hybrid non-road mobile machinery by real-time virtual prototyping", Lappeenranta University of Technology, Lappeenranta, Finland on the 12th of January, 2018.

[5] T. Minav, "Electric-drive-based control and electric energy regeneration in a hydraulic system", Lappeenranta University of Technology, Lappeenranta, Finland, on the 12th of August, 2011.

[6] Specalog for 336E H Hydraulic Excavator, AEHQ6904-01, Available: http://s7d2.scene7.com/is/content/Caterpillar/C811713

[7] V. Jovanovic, "A contribution to the synthesis of the slewing platform drive mechanism of hydraulic excavators", Doctoral Dissertation, University of Nis, Faculty of Mechanical Engineering, UDK:621.879.45+621.879.48]:519.6(043.3), Niš, 2018.

[8] K. Heybroek, "On Energy Efficient Mobile Hydraulic Systems with Focus on Linear Actuation", Dissertations No. 1857, Division of Fluid and Mechatronic Systems, Department of Management and Engineering, Linköping University, SE-581 83 Linköping, Sweden, 2017.

[9] L. Sangyoon, Perry Y. L., A Hardware-In-The-Loop (HIL) Testbed for Hydraulic Transformers Research, The 15th Scandinavian International Conference on Fluid Power, SICFP'17, June 7-9, Linköping, Sweden, 2017.

[10] W. Shen, J. Jiang, X. Su, H. R. Karimi, Parameter matching analysis of hydraulic hybrid excavators based on dynamic programming algorithm, Hindawi Publishing Corporation Journal of Applied Mathematics Volume 2013, Article ID 615608, http://dx.doi.org/10.1155/2013/615608, 2013.

[11] R. Leifeld, M. Vukovic, H. Murrenhoff, "Hydraulic Hybrid Architecture for Excavators," ATZ off highway worldwide, vol. 9, no. 3, pp. 44-49, 2016. [Online]. Available: https://link.springer.com/article/ 10.1007/s41321-016-0523-9

[12] Q. Wang, B. Hu, W. Gong, "Development of hybrid powered hydraulic construction machinery", Automation in Construction, vol. 19, pp. 11-19, 2010.

[13] D. Janošević, V. Jovanović, "Sinteza pogonskih mehanizama hid-rauličkih bagera", monografija, ISBN 978-86-6055-067-7, CIP 621.879-82, Mašinski fakultet Univerziteta u Nišu, 2015. 